\title{
The influence of dual infection with herpes and influenza viruses on the differential blood cell count of mice
}

\author{
L. ANČICOVÁ ${ }^{1}$, V. DUGOVIČOVÁ2, K. BRIESTENSKÁ ${ }^{1}$, F. KOSTOLANSKÝ2, \\ E. VAREČKOVÁ $2^{*}$, J. MISTRÍKOVÁ ${ }^{1,2^{*}}$
}

\begin{abstract}
${ }^{1}$ Faculty of Natural Sciences, Department of Microbiology and Virology, Comenius University in Bratislava, Mlynská dolina, Ilkovičova 6, 84215 Bratislava 4, Slovak Republic; ${ }^{2}$ Biomedical Research Center, Institute of Virology, Slovak Academy of Sciences, Dúbravská cesta 9, 84505 Bratislava, Slovak Republic
\end{abstract}

Received August 18, 2016; revised September 23, 2016; accepted November 7, 2016

\begin{abstract}
Summary. - Based on our previous results, which confirmed the role of latent gammaherpesvirus infection in alteration of immune homeostasis, we studied the influence of simultaneous infection with gammaherpes and influenza viruses on selected parameters of innate immunity, particularly on the subpopulations of peripheral blood cell leukocytes. The aim was to analyze changes of differential blood cell count of BALB/c mice persistently infected with murine gammaherpesvirus 68 (MHV-68) and subsequently co-infected with influenza A virus (IAV), in comparison to mice infected with MHV-68 or with IAV only. Our results showed that ongoing gammaherpesvirus latency in mice caused a decreased number of leukocytes after acute infection with IAV in comparison to a single acute IAV infection. However, increased proportion of neutrophils was measured in peripheral blood of IAV- infected and co-infected mice. Dual infection had no effect on the proportion of monocytes or basophilic and eosinophilic granulocytes. The number of atypical lymphocytes, usually accompanying the persistent infection with MHV-68, decreased in co-infected mice as a consequence of the acute infection with IAV. Persistent infection with gammaherpesvirus may thus modulate the host immune response to influenza A virus and the acute IAV infection can influence the immune homeostasis established by latent MHV-68 infection.
\end{abstract}

Keywords: MHV-68; influenza; dual infection; differential blood cell count

\section{Introduction}

Mammalian hosts, including humans, are naturally exposed to several infectious agents. Influenza viruses belong to the most common pathogens causing frequent infections of the respiratory tract and, simultaneously, most of humans are persistently infected with gammaherpesviruses. It is obvious that co-infection with herpes and influenza viruses occurs often. Recent research studies hypothesized that MHV-68 la-

*Corresponding authors. E-mail: virumis@savba.sk, viruevar@ savba.sk; phone: +421-2-60296-485, +421-2-59302427.

Abbreviations: $\mathrm{dpi}=$ days post infection; $\mathrm{IAV}=$ influenza $\mathrm{A}$ virus; MHV-68 = murine gammaherpesvirus 68; EBV = Epstein-Barr virus; p.i. $=$ post infection tency would modulate the host immune response to influenza A virus (IAV) (Saito et al., 2013; Hardisty et al., 2014).

Our previous results confirmed that co-infection with herpes and influenza viruses could be mutually beneficial for the host by promoting its defense against both viruses (Ančicová et al., 2015). Similar results were obtained with cytomegalovirus, a virus persisting in a latent form in most people worldwide (Furman et al., 2015). Young mice experimentally infected with murine cytomegalovirus were significantly protected from an influenza virus challenge, in contrast to naive mice infected only with influenza virus. These data show that cytomegalovirus and its murine equivalent might have a beneficial effect on the immune response of the young (Furman et al., 2015).

The murine gammaherpes virus 68 (MHV-68), the subfamily Gammaherpesvirinae, the family Herpesviridae, the 
genus Rhadinovirus) represents a model virus for study of the human pathogens, namely Epstein-Barr virus (EBV) (Rickinson et al., 1989; Stevenson et al., 1998). These viruses cause a lymphoproliferative disease resulting in tumor formation, especially in immunosupresssed patients (Mistríková et al., 1999).

The primary infection with MHV-68 virus with visible clinical symptoms leads to the atrophy of thymus and spleen (Sunil-Chandra et al., 1994). On the other hand, an asymptomatic infection is accompanied by lymphoproliferation and splenomegaly (Mistrikova et al., 2000). The highest virus titer in lungs is observed from $5^{\text {th }}$ to $10^{\text {th }}$ day after the infection (Mistríková et al., 2000, 2002). After three to four weeks from the beginning of the infection, the acute phase subsides and the lifelong latency is established in B-lymphocytes, macrophages, dendritic and epithelial cells (Mistríková et al., 1994). Atypical forms of lymphocytes are visible in blood of acutely and persistently MHV- infected mice (Mistríková and Mrmusová, 1998). MHV as well as EBV could be reactivated from the latency as a result of the influence of different stressing factors (Mistríková et al., 1999, 2000). The molecular mechanisms of this process are the subject of many studies, however, specific exogenous triggers are still not exactly defined. Clinical and experimental evidence indicate that co-infection with other pathogens can serve as a stimulus for reactivation of the gammaherpesvirus in latently infected host.

Influenza A viruses cause acute respiratory disease, which spreads among humans epidemically, rarely they cause also pandemics. The high variability of IAV is the reason why influenza infections emerge repeatedly. The course of influenza infection can be often severe, especially when patient suffers from other disease (e.g. cardiovascular), or from immune discomfort (innate immunity, surgical procedure, co-infection with other pathogens). The severity of the course of IAV infection is influenced by the immune potential of the infected organism, including innate and specific immunity (Saito et al., 2013; Hardisty et al., 2014; Ančicová et al., 2015).

The aim of this work was to examine the changes in parameters of innate immunity after influenza infection in persistently infected mice. Because MHV-68 virus was shown to be a suitable model for the establishment of persistent infections in mice (Mistríková et al., 2000; Čipková-Jarčušková et al., 2013), we used it in our experiments with the aim to examine how the persistent infection will modulate the immune-competence of the organism, namely the leukocyte profile, respectively their subpopulations, as parameters of innate immunity during acute influenza infection.

\section{Materials and Methods}

Cells. Madin-Darby Canine Kidney (MDCK) epithelial cells, Vero cells and NIH 3T3 cells were cultured in Dulbecco's modi- fied Eagle's medium (DMEM) supplemented with $10 \%$ of heatinactivated fetal bovine serum (FBS), $2 \mathrm{mmol} / \mathrm{l}$ glutamine, penicillin and streptomycin (100 units $/ \mathrm{ml}$ ). Cell cultures were grown in a $5 \%$ $\mathrm{CO}_{2}$ humidified atmosphere at $37^{\circ} \mathrm{C}$.

Viruses. MHV-68 stock (isolated from Myodes glareolus, Blaškovič et al., 1980) was prepared by virus propagation on NIH $3 \mathrm{~T} 3$ cells and the titer of infectious virus was determined by plaque assay using Vero cells as described (Ančicová et al., 2015). Influenza A/Mississippi/1/85 (H3N2) virus was propagated in embryonated chicken eggs and adapted to BALB/c mice as previously (Fislová et al., 2009). Infectious allantoic fluid of mouse-adapted virus was aliquoted and stored at $-80^{\circ} \mathrm{C}$.

Animal experiments. Female 6-week-old inbred BALB/c mice were supplied by the Faculty of Veterinary Medicine, Brno, Czech Republic.

Infection of mice. Female 6-week-old BALB/c mice were intranasally infected with $2 \times 10^{4} \mathrm{PFU}$ of MHV-68 per mouse in total inoculum volume of $20 \mu \mathrm{l}$, under light anesthesia. Forty-five days after herpesvirus infection, mice were intranasally infected with mouse-adapted influenza virus A/Mississippi/1/85 (H3N2). A sublethal dose $0.4 \mathrm{LD}_{50}$ of IAV ( $40 \mu \mathrm{l} /$ mouse) was used for infection. Control group of mice received the appropriate volume of phosphate buffered saline (PBS). Animals were divided into three experimental groups (12 mice/group: MHV infection, IAV infection and co-infection) and a control group comprising 6 animals. Samples of organs and blood were collected from 4 animals from each infected group and 2 mice from the control group at each time point (on day 3,6 and 10). All animal experiments were performed according to the European Union standards, and fundamental ethical principles including animal welfare requirements were respected. All experiments were done with the approval of State Veterinary and Food Administration of the Slovak Republic (2937/10221).

Blood sample analysis. Blood for serum preparation and leukocytes examination was taken from sinus orbitalis. Heparinized blood was used to determine the total leukocyte count and differential blood cell count (DBC count). The total leukocyte count was determined after staining with Türck's solution. In order to determine DBC count, air dried smears were stained for $10 \mathrm{~min}$ with May-Grünwald solution and then for 15 min with GiemsaRomanowski solution. The stain solution was removed by rinsing with tap water and the smears were examined microscopically using a 100x magnification.

Detection of viral DNA. Total DNA was extracted from $200 \mu \mathrm{l}$ of homogenized organ suspensions using Wizard ${ }^{\circledR}$ Genomic DNA Purification Kit (Promega). Total DNA was used as a template in nested PCR using primers amplifying the M7/gp150 gene of MHV68: M7 FW1: 5'-CTCGAACAACAATCCCACTACA-3' and M7 REV1: 5'- CGTATCCAAAGCAGGGTAGAAA-3'; M7 FW2: 5'- GCCCAAAATGGTGAGAGTGTA 3' and M7 REV2: 5'- GGTGGGTTCATCTTCCTGATT-3'.

Rapid culture assay (RCA). The level of infectious IAV was estimated by RCA: the appropriate dilutions of virus samples (lung cell homogenates) $(100 \mu \mathrm{l})$ were added to MDCK cells cultured in 
96-well plates. Infectious virus from samples was adsorbed onto the cell monolayer $\left(45 \mathrm{~min}\right.$ at $\left.25^{\circ} \mathrm{C}\right)$. Cell monolayers were washed with PBS and $100 \mu$ of serum-free ULTRA-MDCK medium containing $4 \mu \mathrm{g} / \mathrm{ml}$ of TPCK-trypsin was added per well and incubated at $37^{\circ} \mathrm{C}$ in a humid atmosphere of $5 \% \mathrm{CO}_{2}$. After $18 \mathrm{hr}$ of infection, multiple washings of cell monolayers with PBS and fixation with cold methanol at $+4^{\circ} \mathrm{C}$ for $15 \mathrm{~min}$ were done. Infectious virus was detected by monoclonal antibody 107L, specific for influenza A nucleoprotein (Varečková et al., 1995) and the horse-radish peroxidase-conjugated anti-mouse IgG as previously described. The reaction was stopped after $1 \mathrm{hr}$ incubation at $37^{\circ} \mathrm{C}$ and visualized after the addition of the substrate solution $(100 \mu \mathrm{l} /$ well $)$ of 3-amino-9-ethylcarbazol containing hydrogen peroxide (0.03\%) (Varečková et al., 2002). The results were evaluated microscopically after $30 \mathrm{~min}$ incubation at $25^{\circ} \mathrm{C}$ and washing. Distinctly red-colored cells were considered as positive for infection. The titer of infectious virus was determined as the reciprocal value of the highest virus sample dilution, at which still differentiated red intracellular staining of cells was visible.

Statistical analysis. One-way ANOVA was performed using GraphPad Prism version 5.00 in all cases.

\section{Results}

We examined the selected parameters of innate immunity, particularly differential blood cell count (DBC count) and the course of infection in MHV-68-IAV co-infected mice. These were compared with that of IAV-infected or MHV-68 persistently infected mice. BALB/c mice were infected with MHV-68 virus and after the persistent infection was estab- lished, i.e. 45 days post infection (dpi), they were infected with sublethal dose of IAV virus A/Mississippi/1/85(H3N2) of medium virulence (Fislová et al., 2009). Differences in the course of infection in mice infected with single virus (IAV or MHV-68) and co-infected with these two viruses were apparent. While persistent infection established by MHV-68 virus was asymptomatic, the infection with IAV caused acute respiratory disease with typical clinical symptoms in both groups, single IAV- or double MHV-68-IAV-infected mice. Necropsy confirmed the lung lesions in mice infected with IAV at all time points, i.e. 3, 6 and 10 days after the IAV infection (results not shown). The blood for analysis was taken at the same time points from mice in all experimental groups. A more significant leukopenia was observed in single IAV- or double MHV-68-IAV-infected mice when compared to IAV non-infected controls, represented by group of naïve and persistently infected mice (Fig. 1). Levels of leukocytes decreased by $33 \%$ (IAV) and $51 \%$ (IAV-MHV-68) on day 3 and by $42 \% / 47 \%$ on day 6 , respectively. On day 10 p.i., the number of leukocytes slightly increased and approached to the original values present in healthy or persistently $\mathrm{MHV}$ 68-infected mice.

Further, we analyzed the proportion of different subpopulations of leukocytes (lymphocytes, monocytes, neutrophils, eosinophils, basophils and atypical lymphocytes) in IAV-infected and co-infected mice. The most significant were changes in the levels of lymphocytes (decrease) and neutrophils (increase) triggered by IAV infection, regardless whether the mice were infected only with IAV, or were MHV-68-IAV co-infected. The proportion of lymphocytes

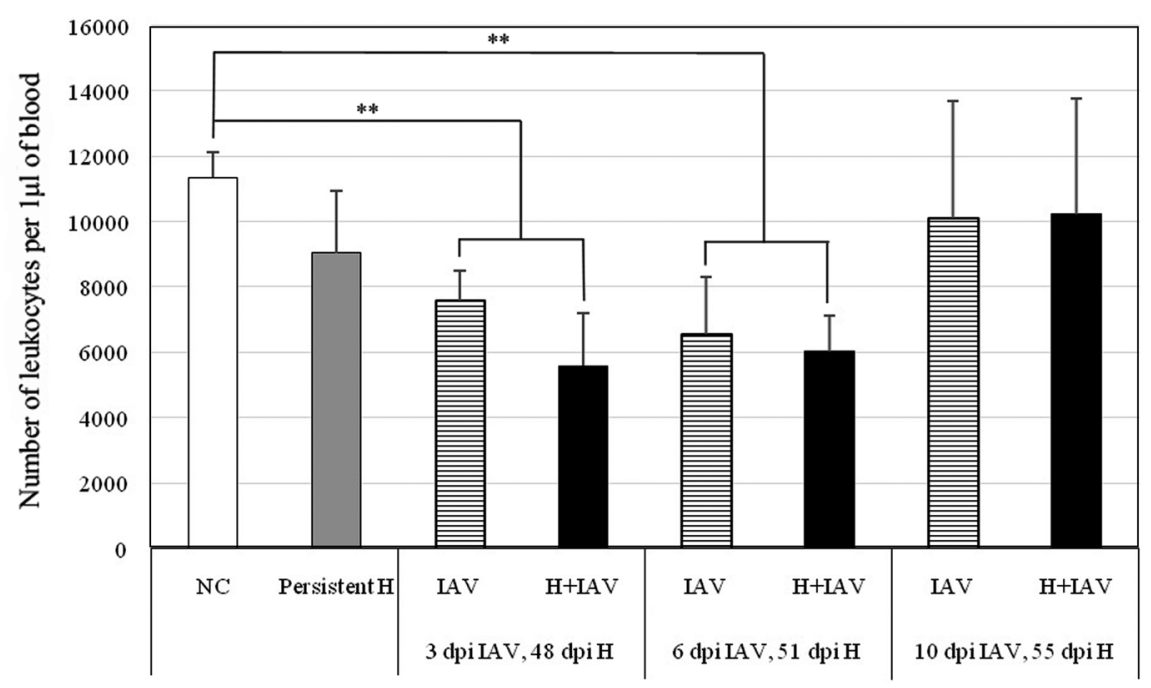

Fig. 1

Number of leukocytes in peripheral blood of persistently infected mice after co-infection with influenza A virus The value for each group represents the mean \pm standard deviation $(n=4)$. Influenza A-infected mice $(\mathrm{IAV}), \mathrm{MHV}-68$-infected mice $(\mathrm{H})$, influenza and MHV-68 co-infected mice (IAV+H-IAV), negative control mice (NC). 
decreased on the $3^{\text {rd }}$ day after IAV infection by about $20 \%$. In persistently infected mice, the decrease of lymphocytes caused by IAV infection was milder than in mice infected with IAV only. The proportion of lymphocytes in blood of these two groups started to increase later after IAV infection and approached the original values on day 10 p.i.

In contrast, the levels of neutrophils significantly increased on the $3^{\text {rd }}$ day after IAV infection (up to 3 times) in comparison to IAV non-infected controls (i.e. naïve-healthy mice and MHV-persistently infected mice). On day 6 p.i., neutrophil levels dropped slowly but did still not reach the original value on $10^{\text {th }}$ day after IAV infection. The level of neutrophils in IAV-infected mice decreased more rapidly than in co-infected mice.

The levels of monocytes, however, increased only mildly as the result of IAV infection in single IAV- or double-infected mice. Similarly, the changes in percentage of eosinophils and basophils were only negligible and values were comparable

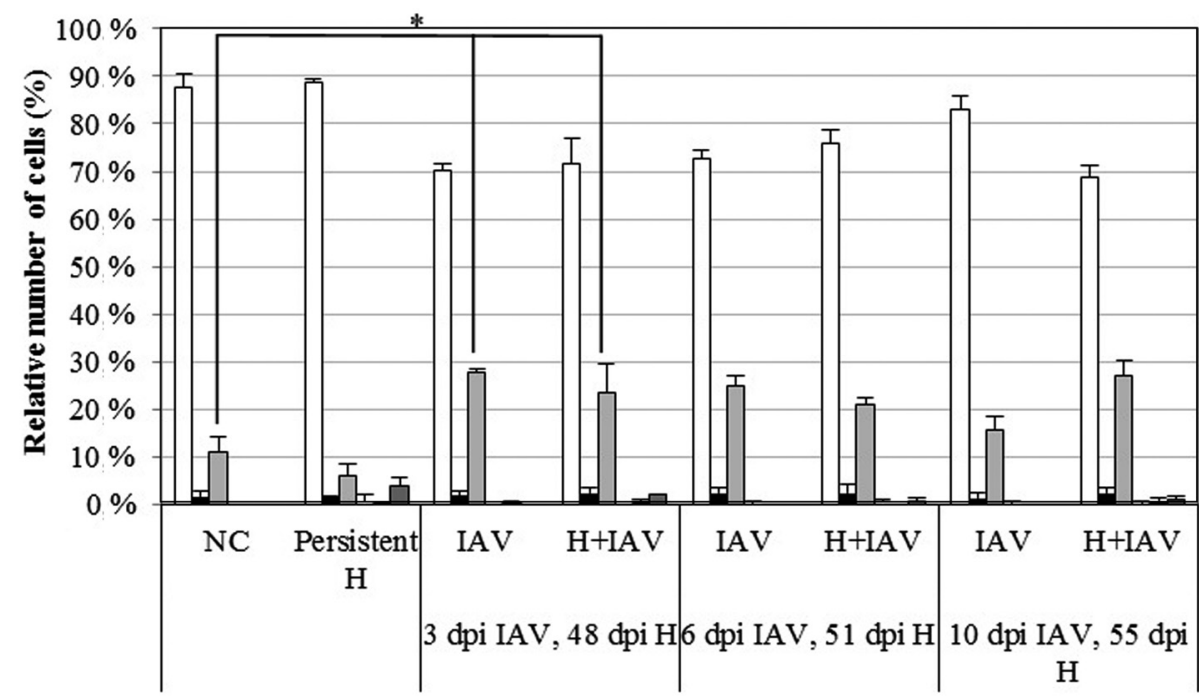

$\square$ Lymphocytes

- Monocytes

$\square$ Neutrophils

\# Eosinophils

๑Basophils

口Atypical lymphocytes

Fig. 2

Proportions of leukocyte counts in persistently infected mice after co-infection with influenza A virus

The value for each group represents the mean \pm standard deviation $(n=4)$. Leukocyte values $(\%)$ were determined from peripheral blood. Influenza Ainfected mice (IAV), MHV-68-infected mice (H), influenza- and MHV-68 co-infected mice (H-IAV), negative control mice (NC).

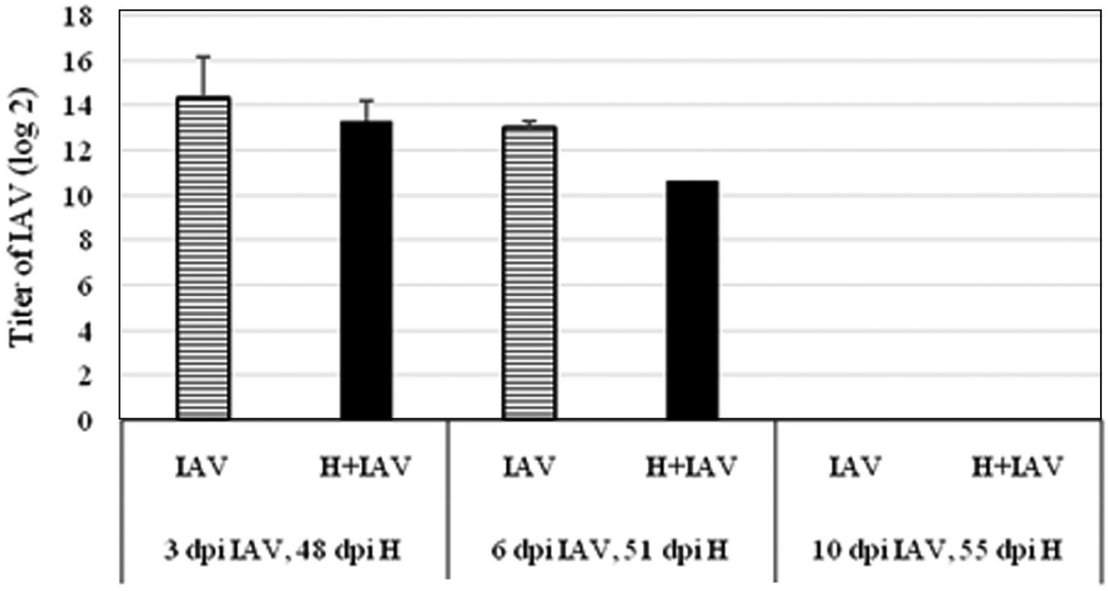

Fig. 3

Detection of influenza virus titer in lungs of infected and co-infected mice 
to negative control group, as well as to MHV-68 persistently infected group of mice.

It was shown that the atypical forms of lymphocytes occur during the persistent MHV-68-infection (Mistríková and Mrmusová, 1998). Therefore, we evaluated here their presence in mice of all experimental groups. We found that the frequency of occurrence of atypical lymphocytes was lower in MHV-68-IAV co-infected mice than in persistently infected mice (Fig. 2).

To understand how the persistent infection influences the course of IAV infection, the IAV viral loads in lungs of mice in groups of IAV-infected and co-infected mice were monitored (Fig. 3). The highest titer of infectious virus was detected on the $3^{\text {rd }} \mathrm{dpi}$ in both examined groups and its level decreased until $10 \mathrm{dpi}$, when no IAV was detected in either group. On day 6 p.i., however, the IAV titer was lower in lungs of co-infected mice than in mice infected with IAV only. Simultaneously, we showed that the reactivation of MHV-68 virus was lower in IAV co-infected mice than in single MHV-68 persistently infected mice at all examined time points (3, 6 and 10 days after IAV infection, i.e. days 48, 51 and 55 after MHV-68 infection, respectively). The presence of MHV-68 infection in our experimental model was confirmed by PCR-detection of the gene encoding envelope glycoprotein 150 (gp150, gene M7) as a marker of infection at all examined time points.

Constant levels of virus-neutralizing antibodies specific to MHV-68 have been detected in sera of mice at all examined time points during the MHV-68 persistent infection (Mistríková et al., 1994). Here we showed that IAV infection of MHV-68 persistently infected mice did not significantly influence the titers of these antibodies in sera collected during the monitored period, neither shortly after the IAV infection (1-10 dpi) nor at later time points (data not shown) (Table 1).

\section{Discussion}

Up today, only several reports about co-infection of persistently infected individuals were published. The co- infection with EBV and Plasmodium falciparum is considered to be related to the Burkitt lymphoma in the region of equatorial Africa (Haque et al., 2004). Other studies about co-infection with gammaherpesvirus and malaria demonstrated that an acute gammaherpesvirus infection has a negative impact on the development of an anti-malarial immune response. This suggests that acute infection with EBV should be investigated as a risk factor for non-cerebral severe malaria in young children living in areas endemic for Plasmodium falciparum (Matar et al., 2015). These findings allow a different view on the understanding of host-virus interactions and suggest the mutual modulation of the immune response of organism to individual pathogens during the co-infection. This has important implications for the herpesvirus shaping of immunity (Reese, 2016). Recent studies identified a critical role of helminth-induced IL-4/ IL-13 and STAT6 activity in reactivation of latent gammaherpesvirus infection in macrophages, which indicates a conserved mechanism of innate immunomodulation in the context of virus-helminth co-infection (Osborne et al., 2014; Reese et al., 2014; Degarege and Erko, 2016). Marandu et al. (2015) studied immune protection against influenza, West Nile virus and vesicular stomatitis virus in aging mice during latent herpes viral infection. In vitro and in vivo analysis of co-infection with swine influenza and porcine reproductive and respiratory syndrome virus showed that co-infection demonstrated additive effects on the expression of several types of virally induced transcripts. These studies iniciated the research in the field of simultaneous infection with multiple pathogens.

Leukopenia was described before as a characteristic sign accompanying the IAV infection, depending on the virulence of IAV (Kostolanský et al., 2013). We showed here that IAV infection led to a more substantial leukopenia in persistently infected mice than in naive mice. However, the decrease was only temporal, as the level of leukocytes increased and reached the level of control non-infected (naïve) mice on day 10 post IAV infection and it even slightly exceeded the level of leukocytes in persistently MHV-68-IAV non-infected

Table 1. Analysis of reactivation MHV-68 infected (H) and MHV-68-IAV co-infected (HI) mice in relation to MHV-68-specific antibody response

\begin{tabular}{|c|c|c|c|c|}
\hline & & $\begin{array}{l}48 \text { dpi } H, \\
3 \text { dpi IAV }\end{array}$ & $\begin{array}{l}51 \text { dpi H, } \\
6 \text { dpi IAV }\end{array}$ & $\begin{array}{l}55 \text { dpi H, } \\
10 \text { dpi IAV }\end{array}$ \\
\hline \multirow[t]{2}{*}{ Presence of infectious virus } & $\mathrm{H}^{(\mathrm{a})}$ & $15 \%$ & $15 \%$ & $10 \%$ \\
\hline & $\mathrm{HI}^{(\mathrm{a})}$ & $7.7 \%$ & $7.7 \%$ & $7.7 \%$ \\
\hline \multirow[t]{2}{*}{ Detection of gp 150} & $\mathrm{H}^{(\mathrm{b})}$ & + & + & + \\
\hline & $\mathrm{HI}^{(\mathrm{b})}$ & + & + & + \\
\hline \multirow{2}{*}{ VN anti- MHV-68 } & $\mathrm{H}^{(\mathrm{c})}$ & 32 & 32 & 32 \\
\hline & $\mathrm{HI}^{(\mathrm{c})}$ & $16-32$ & $16-32$ & $16-32$ \\
\hline
\end{tabular}

(a) The percentage of organs positive for infectious MHV-68 virus of the total examined organs (100\%) (blood, lungs, thymus, heart, spleen, liver, kidney, bone marrow, small intestine, brain); (b) positivity for vDNA encoding gp 150/M7; (c) titer of antibodies neutralizing MHV-68 virus. 
mice. The degree of leukopenia in the group of co-infected mice correlated with the IAV viral load maximum in lungs of co-infected mice.

It is known that MHV-68 as a lymphotropic virus stimulates lymphocytes for proliferation (Mistríková and Mrmusová, 1998). However, IAV infection of mice persistently infected with MHV-68 led to the decrease of lymphocytes proportion in peripheral blood and on day 10 post IAV infection, it remained at lower levels than in the group of non-infected or persistently infected mice. On the other hand, the level of lymphocytes in IAV-infected mice returned to the value comparable to that of negative control (IAV non-infected mice) at the same time point.

Kinetics of IAV replication differs depending on the virulence of IAV and the infectious titer in lungs of mice peaks within 1-3 days after the infection (Fislová et al., 2009). In our study we used the sub-lethal dose of medium virulent IAV, which led to the maximal viral load on day 3 post IAV infection. We showed that such kinetics was preserved also after IAV infection of persistently infected mice and the maximal viral load in mouse lungs coincided with the maximum extent of leukopenia as well as with the maximal level of neutrophils.

\section{Conclusion}

Our results showed that the acute IAV infection of MHV68 persistently infected individuals triggers the alteration of the parameters of innate immunity, which can result in changes of the course of influenza infection and, consequently, in changes of pathogenesis of acute respiratory infection or in reactivation of herpesvirus from latency. The impact of such co-infection on leukocyte number and the proportion of their subpopulation could be dependent on the IAV virulence and on infectious dose of IAV, as we showed in the case of simple IAV infection (Kostolanský et al., 2013), but it could depend also on the HA subtype or host origin of IAV virus, which needs to be elucidated in future studies.

Acknowledgement. This work was supported, by grants from the Scientific Grant Agency of Ministry of Education of Slovak Republic and Slovak Academy of Sciences: VEGA No. 1/0617/15, VEGA 2/0146/15, VEGA 2/0100/13, and by grant APVV-0250-10 from the Slovak Research and Development Agency.

\section{References}

Ančicová L, Wágnerová M, Janulíková J, Chalupková A, Hrabovská Z, Kostolanský F, Varečková E, Mistríková J (2015): Simultaneous infection with gammaherpes and influenza viruses enhances the host immune defense. Acta Virol. 59, 369-379. https:/doi.org/10.4149/av $201504 \quad 369$
Blaškovič D, Stančeková M, Svobodová J, Mistríková J (1980): Isolation of five strains of herpesviruses from two species of free living small rodents. Acta Virol. 24, 468.

Čipková-Jarčušková J, Chalupková A, Hrabovská Z, Wágnerová M, Mistríková J (2013): Biological and pathogenetic characterization of different isolates of mouse gammaherpesvirus MHV-68 in context to study of human oncogenic gammaherpesviruses. Acta Virol. 57, 105-112. https:/doi. org/10.4149/av 2013 $02 \quad 105$

Degarege A, Erko B (2016): Epidemiology of plasmodium and helminth coinfection and possible reasons for heterogeneity. Biomed Res. Int. 2016, ID 3083586, p. 1-6.

Dobrescu I, Levast B, Lai K, Delgado-Ortega M, Walker S, , Banman S, Townsend H, Simon G, Zhou Y, Gerdts V, Meurens F (2014): In vitro and ex vivo analyses of co-infections with swine influenza and porcine reproductive and respiratory syndrome viruses. Vet. Microbiol.169, 18-32. https:/doi. org/10.1016/j.vetmic.2013.11.037

Fislová T, Gocník M, Sládková T, Ďurmanová V, Rajčáni J, Varečková E, Mucha V, Kostolanský F (2009): Multiorgan distribution of human influenza A virus strains observed in a mouse model. Arch Virol. 154, 409-419. https:/doi. org/10.1007/s00705-009-0318-8

Furman D, Jojic V, Sharma S, Shen-Orr SS, Angel CJ, OnengutGumuscu S, Kidd BA, Maecker HT, Concannon P, Dekker CL, Thomas PG, Davis MM (2015): Cytomegalovirus infection enhances the immune response to influenza. Sci. Transl. Med. 7, 281ra43. https:/doi.org/10.1126/ scitranslmed.aaa2293

Haque A, Rachinel N, Quddus MR, Haque S, Kasper LH, Usherwood $E$ (2004): Co-infection of malaria and $\gamma$ - herpesvirus: exacerbated lung inflammation or cross-protection depends on the stage of viral infection. Clin. Exp. Immunol. 138, 396404. https:/doi.org/10.1111/j.1365-2249.2004.02652.x

Hardisty G, Nicol M Q, Ligertwood Y, Bryson K, Hopkins J, Dutia BM (2013): Acute Influenza A pathogenesis is ameliorated in murine model of latent gammaherpesvirus infection. Immunology 140 (Suppl. 1), 39-184.

Kostolanský F, Dugovičová V, Janulíková J, Mucha V, Mistríková J, Varečková E (2013): Virus dose-dependent neutrophil and lymphocyte proportions in peripheral blood during influenza A infection of mice. Acta Virol. 57, 474-476. https:/doi.org/10.4149/av $201304 \quad 474$

Matar CG, Anthony NR, O'Flaherty BM, Jacobs NT, Priyamvada L, Engwerda CR, Speck SH, Lamb TJ (2015): Gammaherpesvirus Co-infection with Malaria Suppresses Anti-parasitic Humoral Immunity. PLoS Pathog. 11, e1004858. https:/ doi.org/10.1371/journal.ppat. 1004858

Mistríková J, Remenová A, Lesso J, Stanceková M (1994): Replication and persistence of murine herpesvirus 72 in lymphatic system and peripheral blood mononuclear cells of Balb/C mice. Acta Virol. 38, 151-156.

Mistríková J, Mrmusová M (1998): Detection of abnormal lymphocytes in the blood of Balb/c mice infected with murine gammaherpesvirus strain 72: the analogy with EpsteinBarr virus infection. Acta Virol. 42, 79-82.

Mistríková J, Mrmusová M, Durmanová V, Rajcáni J (1999): Increased neoplasm development due to immunosup- 
pressive treatment with FK-506 in BALB/C mice persistently infected with the mouse herpesvirus (MHV-72). Viral Immunol. 12, 237-247. https:/doi.org/10.1089/ vim.1999.12.237

Mistríková J, Rašlová H, Mrmusová M, Kúdelová M (2000): A Murine Gammaherpesvirus. Acta Virol. 44, 211-226.

Mistríková J, Mosko T, Mrmusová M (2002): Pathogenetic characterization of a mouse herpesvirus isolate Sumava. Acta Virol. 46, 41-46.

Osborne LC, Monticelli LA, Nice TJ, Sutherland TE, Siracusa MC, Hepworth MR, Tomov VT, Kobuley D, Tran SV, Bittinger K, Bailey AG, Laughlin AL, Boucher JL, Wherry EJ, Bushman FD, Allen JE, Virgin HW, Artis D (2014): Coinfection. Virus-helminth coinfection reveals a microbiota-independent mechanism of immunomodulation. Science 345, 578-582. https:/doi. org/10.1126/science. 1256942

Reese TA, Wakeman BS, Choi HS, Hufford MM, Huang SC, Zhang X, Buck MD, Jezewski A, Kambal A, Liu CY, Goel G, Murray PJ, Xavier RJ, Kaplan MH, Renne R, Speck SH, Artyomov MN, Pearce EJ, irgin HW (2014): Coinfection. Helminth infection reactivates latent $\gamma$-herpesvirus via cytokine competition at a viral promoter. Science 345, 573-577. https:/doi.org/10.1126/science. 1254517

Reese TA (2016): Co-infections: Another Variable in the Herpesvirus Latency-Reactivation Dynamic. J. Virol. 90, 5534-5537. https:/doi.org/10.1128/JVI.01865-15
Rickinson AB, Gregory CD, Murray RJ, Ulaeto DO, Rowe M (1989): Cell-mediated imunity to Epstein-Barr virus and the patogenesis of virus-associated B-cell lymphomas. In Dimmock NJ, Minor PD (Ed.): Immune Responses, Virus Infections and Disease. Oxford: IRL Press, pp. 59-83.

Saito F, Ito T, Connett JM, Schaller MA, Carson WF, Hogaboam CM, Rochford R, Kunkel SL (2013): MHV68 Latency Modulates the Host Immune Response to Influenza A Virus. Inflammation 36, 1295-1303. https:/doi.org/10.1007/ s10753-013-9668-1

Stevenson PG, Doherty PC (1998): Kinetic analysis of the specific host response to a murine gammaherpesvirus. J. Virol. $72,943-949$.

Sunil-Chandra NP, Arno J, Fazakerley J, Nash AA (1994): Lymphoproliferative disease in mice infected with murine gammaherpesvirus 68. Am. J. Pathol. 145, 818-826.

Varečková E, Cox N, Klimov A (2002): Evaluation of the subtype specificity of monoclonal antibodies raised against H1and H3 subtypes of human influenza A virus hemagglutinins. J. Clin. Microbiol. 40, 2220-2223. https:/doi.org/10.1128/ LCM.40.6.2220-2223.2002

Varečková E, Betáková T, Mucha V, Soláriková L, Kostolanský F, Waris M, Russ G (1995): Preparation of monoclonal antibodies for the diagnosis of influenza A infection using different immunization protocols. J. Immunol. Methods 180, 107-116. https:/doi.org/10.1016/0022$\underline{1759(94) 00307-\mathrm{I}}$ 